\title{
The surgical strategy for eosinophilic granuloma of the pediatric cervical spine complicated with neurologic deficit and/or spinal instability
}

\author{
Nanzhe Zhong ${ }^{\dagger}$, Wei Xu ${ }^{\dagger}$, Tong Meng ${ }^{\dagger}$, Xinghai Yang, Wangjun Yan and Jianru Xiao*
}

\begin{abstract}
Background: Various therapeutic approaches have been proposed for the treatment of pediatric patients with eosinophilic granuloma (EG) of the cervical spine. Our aim was to discuss and present our experience with the individualized surgical intervention of pediatric cervical EG complicated with neurologic deficits and/or spinal instability.

Methods: We retrospectively analyzed the clinical data of 19 children who were diagnosed with cervical EG comor spinal/or spinal instability (evaluated by the Spinal Instability Neoplastic Score, SINS $\geq 7$ ) and treated surgically in our institution.

Results: Lesions involved $\mathrm{C} 1-2$ in 7 patients and C3-7 in 12 patients. Anterior tumor resection combined with posterior pedicle screw fixation, anterior approach of excision and instrumentation, and posterior tumor resection combined with pedicle screws instrumentation were selected according to the different locations of tumors. Frankel scale and Oucher scale improved significantly after surgery. There was no morphologic alteration of the neck at follow-up.
\end{abstract}

Conclusions: Surgery can significantly improve the neurologic status and symptoms. Surgical decision-making must be individually tailored to minimize the influence of surgery on spine growth.

Keywords: Pediatric, Cervical, Eosinophilic granuloma, Surgery

\section{Background}

Langerhans-cell histiocytosis ( $\mathrm{LCH})$ is a complicated disease entity that can result in either benign or devastating outcomes. Among the clinical spectrum of $\mathrm{LCH}$, eosinophilic granuloma (EG) is the most benign and predominant condition, featured by a clonal proliferation of Langerhans-type cells with bone involvement. In children and young adolescents with this tumor, about $80 \%$ of patients are reported to be younger than 20 years [1].

Although thoracic segments is the most preferential spine localization in EG patients of all ages with vertebral

\footnotetext{
* Correspondence: jianruxiao83@163.com

${ }^{\dagger}$ Equal contributors

Department of Orthopedic Oncology, Changzheng Hospital, Second Military Medical University, 415 Fengyang Road, Shanghai 200003, China
}

involvement [1, 2], data of previous studies and our research has suggested that incidence in the cervical spine is the highest in pediatric patients with spinal EG [3, 4].

The typical vertebral lesion of EG is composed of an osteolytic area causing complete or incomplete collapse and flattening of vertebrae, known as vertebra plana. The bony destruction of vertebral EG might lead to spinal instability with severe mechanical back pain and even a pathological fracture. Pediatric patients with cervical EG can present with symptoms including acute onset of neck pain with/without history of trauma and torticollis or neck stiffness due to restricted motion $[5,6]$. Vertebral collapse and impingement from extradural extension of the lesion may further result in nerve compression and subsequent neural deficit and myelopathy. 
Various therapeutic approaches have been proposed for the treatment of pediatric patients with EG of the cervical spine. For most cases without neural deficits or spinal instability, it is often sufficient to palliate symptoms and induce the lesion regression by conservative treatment and biopsy with cervical collar immobilization in view of the possibility of spontaneous resolution. Surgical intervention should be considered to relieve pain, maintain spinal stability, and preserve neural function in the presence of neurologic compromise, spinal instability, and severe deformity [1]. It has been documented that several surgical strategies are feasible for the achievement of the abovementioned therapeutic goals in the treatment of pediatric cervical EG without growth arrest and ensuing deformity [5, 7]. However, as no randomized clinical trials have been performed on the pediatric cervical EG due to the scarcity of cases and ethical issues, there is no consensus about the optimal surgical procedure regarding surgical approaches and internal fixation methods.

To discuss the most suitable surgical management of pediatric patients with cervical EG, a retrospective study was undertaken reviewing 19 cases of cervical EG complicated with neurologic deficit and/or spinal instability. Herein, we reviewed the clinical features of pediatric cervical EG and presented our experience with the surgical intervention of the disease (Figs. 1 and 2).

\section{Methods \\ Patient samples}

This study was approved by the ethics committee of the Changzheng Hospital of Second Military Medical University. We retrospectively reviewed cases in 19 children ( $\leq 15$ years) who were diagnosed with cervical EG complicated with neurological deficits and/or spinal instability (evaluated by the Spinal Instability Neoplastic Score, SINS $\geq 7$ [8]) and treated surgically between April 2009 and June 2014 in our institution. The exclusion criteria were multiple systems of involvement and those arising in the thoracic and lumbar spine. A frozen biopsy is performed in every surgery to verify the diagnosis on the basis of preoperative clinical data. In addition to the frozen biopsy, a routine histopathologic biopsy is also performed to provide the definite diagnosis. Pain and neurological function were evaluated by Oucher scale and Frankel scale, respectively.
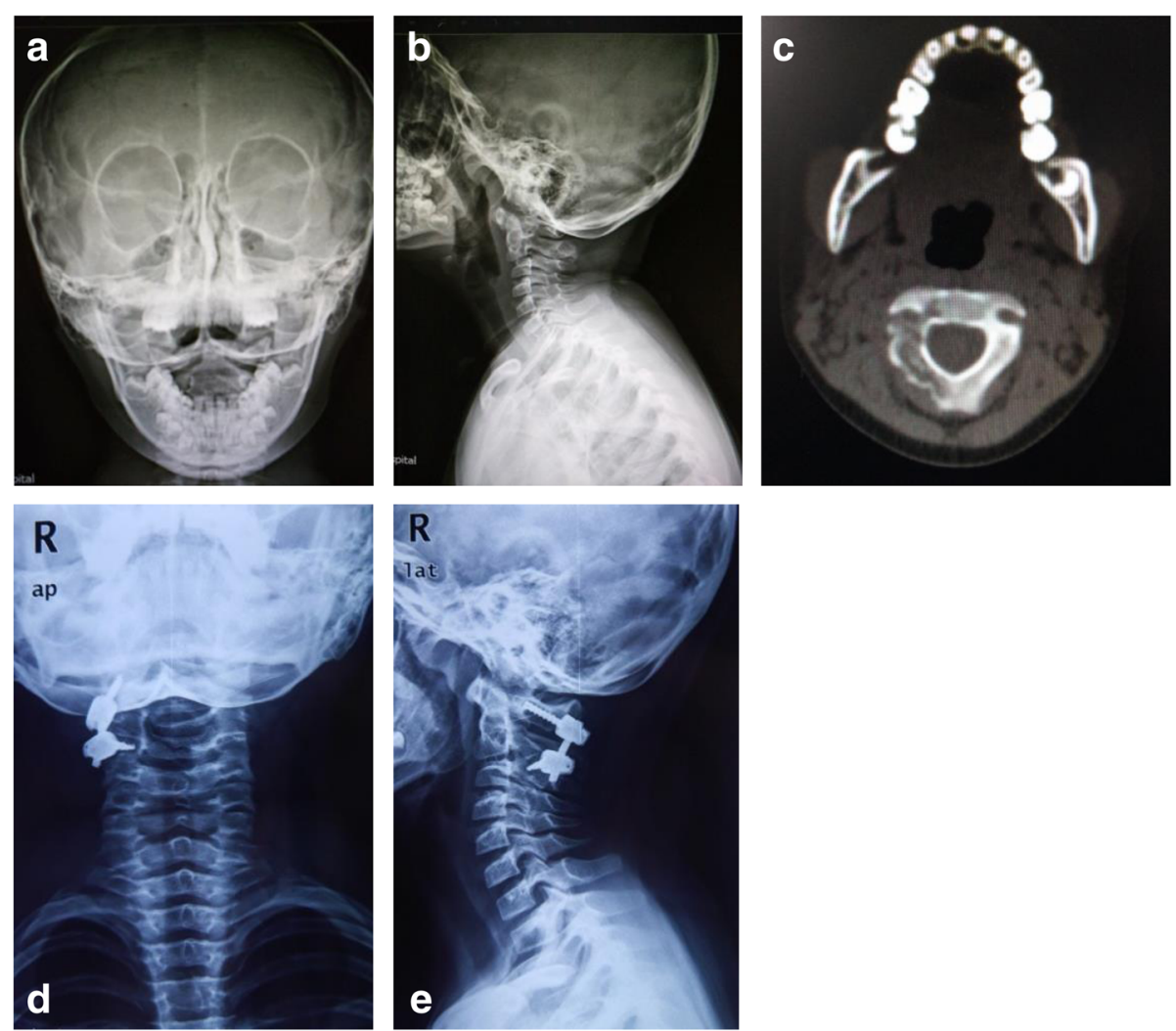

Fig. 1 Case 10: a 5-year-old girl, C2 LCH. a, b Anterioposterior and lateral plain film before operation. c CT scan showed the right appendix of C2 was involved. d, e Anterioposterior and lateral plain film 48 months after operation of anterior tumor resection combined with posterior pedicle screw instrumentation 

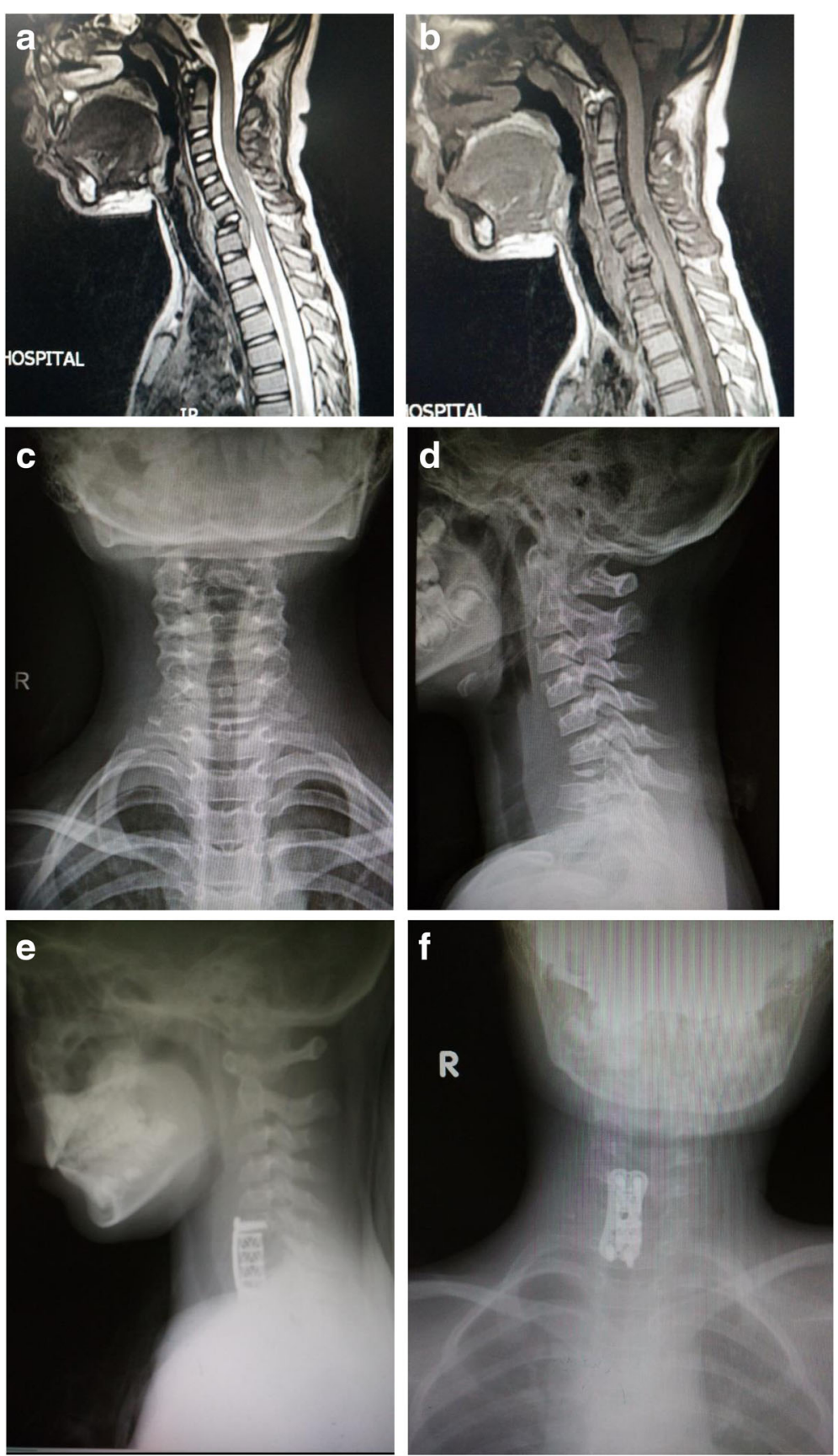

Fig. 2 Case 4: a 7-year-old girl, C7 LCH. a, b T1- and T2-weighted MRI images before operation. c, d Anterioposterior and lateral plain film before operation. e, f Anterioposterior and lateral plain film 15 months after operation of anterior tumor resection and miniplate and screw instrumentation

\section{Treatment (operative procedures)}

The surgical approach was tailored for each patients depending on Weinstein-Boriani-Biagini (WBB) surgical staging system, including posterior approach, anterior approach, or a combination. The instrumentation method (anterior miniplate and screws or posterior pedicle screws) was also individualized in consideration of minimizing motion scarification and influence on growth. All surgeries were performed in one stage.

Postoperatively, patients were prescribed with prednisone $40 \mathrm{mg} / \mathrm{m}^{2} /$ day orally days $1-5$ every 3 weeks for a total treatment duration of 6 months. To reinforce the stability of the cervical spine, patients were immobilized with neck collars for at least 6 months until the fusion of the bones. 


\section{Follow-up}

All patients were followed up in the outpatient clinics at 3-, 6-, and 12-month postoperatively and annually for life thereafter. Outcome including radiographic image (anteroposterior and lateral cervical plain film and MRI) was investigated at each visit, and pubertal status (height, weight, bone maturity) was evaluated every 6 months. The neurologic status and pain were also assessed by Frankel scale and Oucher scale, respectively.

\section{Statistical analysis}

All data were analyzed using SPSS 18.0 analysis software. To compare the pre- and postoperative clinical parameters and outcome, the paired-sample $t$ test was used. Statistical differences are presented at when $p$ values were $<0.05$.

\section{Results}

The cohort consists of 15 boys and 4 girls. The average age of diagnosis was $9.9 \pm 3.1$ years (range, $5-15$ years) with mean height and weight being $143.0 \pm 21.2 \mathrm{~cm}$ and $36.8 \pm 13.3 \mathrm{~kg}$, respectively. The basic clinical data were summarized in Table 1. The mean time from onset to admission was 67.4 days. The results of preoperative laboratory tests showed elevation of erythrocyte sedimentation rate (ESR) in seven cases ranging from 5 to
$44 \mathrm{~mm} / \mathrm{h}$ (normal range, $0 \sim 15 \mathrm{~mm} / \mathrm{h}$ ) and elevation of $\mathrm{C}$-reactive protein in six cases ranging from 0.97 to $42.77 \mathrm{mg} / \mathrm{L}$ (normal range, $<1.0 \mathrm{~g} / \mathrm{L}$ ).

The initial clinical presentation was retrieved from the medical records. The most common initial symptoms were, in descending order, restricted cervical motion (100\%), neck pain $(94.7 \%)$, neurological symptoms $(84.2 \%)$, and torticollis $(26.3 \%)$. The average SINS score was $11.8 \pm$ 2.5. Oucher scale for pain was obtained, with the mean score being $8.1 \pm 1.5$. The neurological status of all the patients was accessed and classified according to Frankel scale. The result reveals 3 patients with Frankel grade C, 14 with grade $\mathrm{D}$, and 2 with grade $\mathrm{E}$ (Table 1 ).

\section{Radiological evaluation}

Preoperative radiographic data of all patients were collected, including antero-posterior and lateral cervical roentgenograms, computed tomography (CT), and magnetic resonance image (MRI). In 7 patients, lesions involved the upper cervical spine $(\mathrm{C} 1-2)$ and in 12 patients, lesions involved the lower cervical spine (C3-7). The distribution of the tumors was evaluated using the Weinstein-Boriani-Biagini (WBB) classification on the basis of layers and zones on CT and MRI findings. In most cases, the tumors involved layers A-D, with only six lesions extended to layers B-D. It is found that

Table 1 Clinical data before treatment

\begin{tabular}{|c|c|c|c|c|c|c|c|c|c|}
\hline No. & Gender & Age & Involved vetebrae & SINS & Frankel & Oucher & WBB & $\begin{array}{l}\text { Height } \\
(\mathrm{cm})\end{array}$ & $\begin{array}{l}\text { Weight } \\
(\mathrm{kg})\end{array}$ \\
\hline 1 & M & 11 & $\mathrm{C7}$ & 7 & $\mathrm{D}$ & 9 & 2 & 150 & 43 \\
\hline 2 & M & 10 & $\mathrm{C7}$ & 13 & $\mathrm{D}$ & 7 & 1 & 145 & 38 \\
\hline 3 & M & 6 & C6 & 8 & $\mathrm{D}$ & 4 & 2 & 120 & 26 \\
\hline 4 & $\mathrm{~F}$ & 7 & $\mathrm{C7}$ & 14 & $\mathrm{D}$ & 6 & 1 & 110 & 18 \\
\hline 5 & M & 6 & C5 & 15 & $\mathrm{D}$ & 8 & 2 & 100 & 12 \\
\hline 6 & M & 11 & $\mathrm{C} 2$ & 16 & $\mathrm{D}$ & 8 & 1 & 152 & 45 \\
\hline 7 & M & 9 & $\mathrm{C} 2$ & 9 & $E$ & 7 & 1 & 141 & 32 \\
\hline 8 & $F$ & 7 & $\mathrm{C} 2$ & 16 & C & 10 & 1 & 122 & 20.5 \\
\hline 9 & M & 15 & C3 & 10 & E & 7 & 1 & 167 & 58 \\
\hline 10 & $\mathrm{~F}$ & 5 & C2 & 12 & $\mathrm{E}$ & 8 & 1 & 120 & 26 \\
\hline 11 & $M$ & 14 & $\mathrm{C} 2$ & 14 & $D$ & 9 & 1 & 160 & 48 \\
\hline 12 & $M$ & 14 & $\mathrm{C} 2$ & 14 & $\mathrm{D}$ & 8 & 1 & 163 & 47 \\
\hline 13 & $M$ & 13 & C5 & 13 & $D$ & 9 & 1 & 159 & 42 \\
\hline 14 & $M$ & 13 & C4 & 12 & $C$ & 8 & 1 & 168 & 53 \\
\hline 15 & $M$ & 11 & $C 7$ & 9 & $D$ & 9 & 1 & 152 & 45 \\
\hline 16 & $M$ & 12 & C4 & 9 & $D$ & 10 & 1 & 169 & 54 \\
\hline 17 & $M$ & 10 & $C 2$ & 14 & $D$ & 10 & 1 & 148 & 36 \\
\hline 18 & $M$ & 9 & C4 & 10 & C & 8 & 2 & 151 & 34 \\
\hline 19 & $F$ & 6 & C6 & 9 & $\mathrm{D}$ & 9 & 1 & 120 & 21 \\
\hline
\end{tabular}

WBB: zones 4-9: 1, zones 10-5: 2 
tumors were located majorly in the anterior column (zones 4-9) in 15 cases and the posterior column (zones $10-5)$ in 4 cases.

\section{Treatment and follow-up}

The customized surgical strategy was designed for each patients depending on the location and extension of the lesion. For the atlantoaxial tumor, anterior tumor resection combined with posterior pedicle screws fixation was performed (seven cases). We selected anterior approach of excision and instrumentation for tumors majorly located on the anterior column (eight cases), and posterior tumor resection combined with pedicle screws instrumentation for those involved posterior elements (four cases).

The mean operation time was $217.1 \pm 40.7,169.8 \pm$ 37.1 , and $131.3 \pm 35.7 \mathrm{~min}$ with the surgical procedure for atlantoaxial $\mathrm{LCH}$, anterior tumor removal and miniplate and screw instrumentation, and posterior tumor resection and pedicle screw fixation, respectively. The mean intraoperative blood loss was $241.4 \pm 191.0 \mathrm{~mL}$ with the combined procedure for atlantoaxial $\mathrm{LCH}$, $165.0 \pm 69.5 \mathrm{~mL}$ with single anterior approach, and $137.5 \pm 45 \mathrm{~mL}$ with single posterior approach. There was no intraoperative complication noted in all patients. Of all patients in our series, no instrumentation failure and cervical deformity was seen at a mean follow-up time of
$36.4 \pm 13.7$ months (range 13-53 months), with a median follow-up time of 41 months. The average height and weight at the last follow-up were $158.1 \pm 14.9 \mathrm{~cm}$ and $50.3 \pm 14.4 \mathrm{~kg}$, respectively (Table 2). Unfortunately, recurrence on thoracic vertebrae was detected 6 months after surgery in one child who did not take prednisone due to remission of symptoms and being afraid of the adverse effects of steroid. She was cured with oral prednisone and brace. All patients with neurological deficits got complete recovery from 1 to 2 weeks after surgery without deterioration during follow-up, illustrated by the significantly improved Frankel grade $(p<0.001)$. Pain was significantly released by treatment, with average Oucher score decreasing from $8.1 \pm 1.5$ to $0.3 \pm 1.4$ $(p<0.001)$ (Table 2). The average duration of the cervical collar immobilization was 4.4 months. Three boys stopped wearing the cervical collar once they had resolution of symptoms. However, bone fusion was achieved in all cases without instrumentation failure. There was no morphologic alteration of the neck and no limitation in rotational movement of the cervical spine observed at follow-up.

\section{Discussion}

$\mathrm{LCH}$ can occur in any age groups but is more common in the pediatric population, with the estimated incidence

Table 2 Clinical data of operation and at the last follow-up

\begin{tabular}{|c|c|c|c|c|c|c|c|c|c|c|}
\hline No. & Surgical procedure & $\begin{array}{l}\text { Operative time } \\
\text { (min) }\end{array}$ & Blood loss & $\begin{array}{l}\text { Follow-up } \\
\text { (month) }\end{array}$ & $\begin{array}{l}\text { Height } \\
(\mathrm{cm})\end{array}$ & $\begin{array}{l}\text { Weight } \\
(\mathrm{kg})\end{array}$ & Frankel & Oucher & $\begin{array}{l}\text { Adjuvant } \\
\text { therapy }\end{array}$ & Recurrence \\
\hline 1 & 3 & 135 & 160 & 53 & 173 & 63 & $E$ & 0 & Oral pred & No \\
\hline 2 & 2 & 179 & 100 & 18 & 152 & 46 & E & 0 & Oral pred & No \\
\hline 3 & 3 & 160 & 100 & 26 & 135 & 37 & $\mathrm{E}$ & 0 & Oral pred & No \\
\hline 4 & 2 & 180 & 160 & 15 & 132 & 26 & E & 0 & Oral pred & No \\
\hline 5 & 3 & 80 & 100 & 38 & 136 & 33 & E & 6 & - & Yes \\
\hline 6 & 1 & 240 & 200 & 52 & 175 & 60 & E & 0 & Oral pred & No \\
\hline 7 & 1 & 240 & 400 & 49 & 156 & 49 & $\mathrm{E}$ & 0 & Oral pred & No \\
\hline 8 & 1 & 210 & 100 & 47 & 151 & 38 & E & 0 & Oral pred & No \\
\hline 9 & 2 & 170 & 300 & 13 & 170 & 64 & E & 0 & Oral pred & No \\
\hline 10 & 1 & 130 & 80 & 48 & 141 & 33 & E & 0 & Oral pred & No \\
\hline 11 & 1 & 250 & 600 & 43 & 172 & 64 & $E$ & 0 & Oral pred & No \\
\hline 12 & 1 & 230 & 120 & 41 & 175 & 69 & $E$ & 0 & Oral pred & No \\
\hline 13 & 2 & 250 & 200 & 50 & 171 & 67 & E & 0 & Oral pred & No \\
\hline 14 & 2 & 180 & 200 & 46 & 174 & 70 & $E$ & 0 & Oral pred & No \\
\hline 15 & 2 & 134 & 100 & 37 & 165 & 62 & E & 0 & Oral pred & No \\
\hline 16 & 2 & 145 & 150 & 14 & 171 & 56 & E & 0 & Oral pred & No \\
\hline 17 & 1 & 220 & 190 & 25 & 152 & 39 & E & 0 & Oral pred & No \\
\hline 18 & 3 & 150 & 190 & 35 & 154 & 42 & E & 0 & Oral pred & No \\
\hline 19 & 2 & 120 & 110 & 42 & 149 & 37 & E & 0 & Oral pred & No \\
\hline
\end{tabular}

Surgical procedure: 1: anterior tumor resection combined with posterior pedicle screw instrumentation; 2 : anterior tumor resection and miniplate and screw instrumentation; 3: posterior tumor resection and pedicle screw instrumentation 
ranging from 2 to 10 per million children $[9,10]$. Although EG of the cervical spine is a rare condition, there is a predominant involvement of cervical spine in pediatric patients with spinal EG [3, 4]. The typical pattern of vertebral destruction can facilitate the establishment of the diagnosis of cervical EG. Nevertheless, a tissue biopsy for histopathologic examination is required to diagnose EG formally. For patients with unifocal osseous lesions, the overall benefits of needle or open biopsy remains controversial [1]. In our practice, for pediatric cervical EG patients suffered from neurological deficits and/or had SINS $\geq 7$, we suggested surgery as an emergent treatment choice to prevent these children from any possible impending disastrous damages. And a frozen biopsy was performed in these surgeries to further clarify the diagnosis on the basis of preoperative clinical data, so as to reconfirm the previously designed surgical modality, or to make a modification accordingly. In addition to the frozen biopsy, a postoperative routine histopathologic examination was also performed to provide a definite diagnosis.

Given the general benign prognosis of spinal EG [11], various therapeutic modalities were employed in pediatric patients without neurological deficits or spinal instability, including chemotherapies, low-dose radiotherapies, and minimally invasive treatments [12-16]. Although lack of consensus, it is generally considered that spine instability, kyphoscoliosis, and neurologic deficiencies and neurologic deficit are major surgical indications for spinal EG [1]. To avoid further disastrous damages resulted from spinal cord compression and cervical instability, we regarded neurologic deficiencies and SINS $\geq 7$ as indications for treating pediatric cervical EG surgically.

Surgical modalities for cervical EG may vary with the extent and location of the disease. For EG of the atlas and axis in adult patients, we have previously reported that anterior tumor resection and posterior reconstruction by posterior occipitocervical fixation or upper cervical fixation can offer eradication of the lesion, decompression of nerve, and immediate atlantoaxial stability [17]. However, in view of preserving the potential growth of spine and improving quality of life, this procedure was performed for pediatric patients with upper cervical EG in our series. C1 and C2 pedicle screw instrumentation technique has been proved to be safe with low complications when it is applied on selected pediatric patients [18]. The data of our study reinforces the statement that this method of fixation can be a safe and effective alternative for pediatric upper cervical EG, minimizing the influence on spine growth and motion.

In comparison, more reports focused on the surgical procedures for lower cervical EG, which included curettage and fusion with or without instrumentation. Denaro et al. [5] described specially modeled autoplastic grafts harvested from the iliac wing, which were inserted after complete excision of the anterior portion of the EG involved vertebral body to maintain normal motion of the adjacent segments and growth of the vertebrae in the long term. Arthrodesis was achieved in patients after immobilization by Minerva cast for 90 days. To handle lesions with greater extent of vertebral destruction, anterior corpectomy would be performed followed by mesh cage and plate instrumentation to obtain fusion in both pediatric and adult patients $[7,19]$. The nuance between this surgery performed in different age group is that the longest possible mesh cage is recommended in children considering spine growth and restoration of the cervical lordosis curve. The principle of our surgical consideration for pediatric cervical EG is minimizing the insults of surgery on the growing spine. For lesions located on the anterior column of the segment of the lower cervical spine, anterior resection of tumor was performed. To reconstruct the stability of spine, autologous bone graft or mesh cage was inserted on the basis of the extension of resection, and anterior mini-plate and screw were used. Correspondence to prior reports, there is no adverse effect on spine curvature detected during the followup and the remission of symptoms was quick [7, 20]. If only the posterior element was destroyed by the tumor, we recommend posterior excision and pedicle screw instrumentation, which is featured by short operation time and small amount of bleeding. It is suggested by $\mathrm{Lu}$ et al. that pedicle screw-based instrumentation and the independent posterior approach is a preferable procedure for children with thoracic and lumbar EG for its minimal trauma and favorable results [21]. Our data supported the conclusion of Lu's study and further proves that posterior approach of tumor removal and instrumentation is also an ideal choice for the individual surgical treatment of selected pediatric cervical EG cases.

There has been no definitive evidence-based conclusion yet to guide the adjuvant therapy after surgical intervention of spinal EG. Opinions vary from only observation to low-dose standard chemotherapy. On the basis of the experience drawn from our clinic and previous report [13], desirable effects and high rate of adherence can be acquired by orally taking prednisolone alone. Furthermore, one patient in the current study who was not compliant with oral prednisolone had recurrent EG on the thoracic vertebrae, suggesting the necessity of systemic intervention of spinal EG instead of only local excision of the tumor. The duration of postoperative immobilization is also under investigation. Patients were asked to wear cervical collars for 6 months to ensure spinal fusion. However, no spinal deformity or instrumentation failure was 
observed even in some children who had worn orthosis for only 1 or 2 months.

\section{Conclusions}

There is an obvious demand for a full assessment of each pediatric cervical EG patient with a rational surgical procedure tailored to the extension and location of the lesion. Limitations of the current study are common to retrospective research in which the data are only as precise as available medical records. Besides, our study has limited power as a result of small numbers and uncontrolled variables. Despite the limitations, our results strongly suggest the application of aforementioned procedures on the specific site of cervical spine and contribute to the individualized surgical treatment of pediatric cervical EG patients complicated with neurologic deficit and/or spinal instability, which is characterized by minimal surgical trauma and effects on spine growth without recurrence. The neural status and symptoms of these patients were significantly improved by the surgical intervention and EG-related cervical deformity was corrected by instrumentation. After all, surgeries for pediatric cervical spine is demanding and require thorough pre-operative planning and special technical expertise to supply an ensurance for the safety and effectiveness both in the operation and in the long term.

\section{Abbreviations}

EG: Eosinophilic granuloma; ESR: Erythrocyte sedimentation rate; LCH: Langerhans cell histiocytosis; SINS: Spine Instability Neoplastic Score; WBB: WeinsteinBoriani-Biagini

\section{Acknowledgements}

No acknowledgements to declare.

\section{Funding}

No source of funding for the research was declared.

\section{Availability of data and materials}

All data analyzed in our research have been presented in the Tables 1 and 2 .

\section{Authors' contributions}

NZ collected and analyzed the clinical data and drafted the manuscript. WX and TM helped to analyze the data and draft the manuscript. XY and WY conducted the follow-up of patients. JX conducted the follow-up of patients and designed the study. All authors read and approved the final manuscript.

\section{Competing interests}

The authors declare that they have no competing interests.

\section{Consent for publication}

As the images of the patients in case 4 and case 10 were used in this manuscript, consent to publish has been obtained from these patients and their parents.

\section{Ethics approval and consent to participate}

All research carried out is in compliance with the Helsinki Declaration. This study was approved by the institutional review board of the Changzheng Hospital of Second Military Medical University.

Received: 14 June 2016 Accepted: 25 November 2016

Published online: 07 December 2016

\section{References}

1. DiCaprio MR, Roberts $\Pi$. Diagnosis and management of Langerhans cell histiocytosis. J Am Acad Orthop Surg. 2014;22:643-52. doi:10.5435/JAAOS-22-10-643.

2. Per H, Koc KR, Gumus H, Canpolat M, Kumandas S. Cervical eosinophilic granuloma and torticollis: a case report and review of the literature. J Emerg Med. 2008:35:389-92. doi:10.1016/j.jemermed.2007.10.026.

3. Kotecha R, Venkatramani R, Jubran RF, Arkader A, Olch AJ, Wong K. Clinical outcomes of radiation therapy in the management of Langerhans cell histiocytosis. Am J Clin Oncol. 2014;37:592-6. doi:10.1097/COC.0b013e318281d6ce.

4. Huang WD, Yang XH, Wu ZP, Huang Q, Xiao JR, Yang MS, Zhou ZH, Yan WJ, Song DW, Liu TL, Jia NY. Langerhans cell histiocytosis of spine: a comparative study of clinical, imaging features, and diagnosis in children, adolescents, and adults. The spine journal : official journal of the North American Spine Society. 2013;13:1108-17. doi:10.1016/j.spinee.2013.03.013.

5. Denaro L, Longo UG, Papalia R, Di Martino A, Maffulli N, Denaro V. Eosinophilic granuloma of the pediatric cervical spine. Spine. 2008;33:E936-941. doi:10.1097/BRS.0b013e3181859aab.

6. Tumturk A, Kaya Ozcora G, Kacar Bayram A, Kabaklioglu M, Doganay S, Canpolat M, Gumus H, Kumandas S, Unal E, Kurtsoy A, Per H. Torticollis in children: an alert symptom not to be turned away. Child's nervous system : ChNS : official journal of the International Society for Pediatric Neurosurgery. 2015;31:1461-70. doi:10.1007/s00381-015-2764-9.

7. Chen SY, Chao SC, Kao TH, Shen CC, Tsou HK. Surgical treatment using mesh cage and plate fixation in a 9-year-old child with solitary histiocytosis lesion in the cervical spine. European journal of pediatric surgery : official journal of Austrian Association of Pediatric Surgery [et al] = Zeitschrift fur Kinderchirurgie. 2011;21:189-91. doi:10.1055/s-0031-1271636.

8. Weber MH, Burch S, Buckley J, Schmidt MH, Fehlings MG, Vrionis FD, Fisher CG. Instability and impending instability of the thoracolumbar spine in patients with spinal metastases: a systematic review. Int J Oncol. 2011;38:5-12.

9. Kim BE, Koh KN, Suh JK, Im HJ, Song JS, Lee JW, Kang HJ, Park KD, Shin HY, Choi HS, Lee SH, Yoo KH, Sung KW, Koo HH, Jung HL, Chung NG, Cho B, Kim HK, Lyu CJ, Baek HJ, Kook H, Park JE, Park HJ, Park BK, Yoo ES, Ryu KH, Lee KS, Kim HS, Lee JM, Park ES, Yoon HS, Lee KC, Lee MJ, Lim YT, Kim HM, Park SK, Park JA, Kim SK, Park M, Lim YJ, Lee YH, Seo JJ, Korea Histiocytosis Working P. Clinical features and treatment outcomes of Langerhans cell histiocytosis: a nationwide survey from Korea histiocytosis working party. J Pediatr Hematol Oncol. 2014;36:125-33. doi:10.1097/MPH.0000000000000054.

10. Maia RC, de Rezende LM, Robaina M, Apa A, Klumb CE. Langerhans cell histiocytosis: differences and similarities in long-term outcome of paediatric and adult patients at a single institutional centre. Hematology. 2015;20:83-92. doi:10.1179/1607845414Y.0000000173

11. Arico M, Astigarraga I, Braier J, Donadieu J, Gadner H, Glogova E, Grois N, Henter Jl, Janka G, McClain KL, Ladisch S, Potschger U, Rosso D, Thiem E, Weitzman S, Windebank K, Minkov M, Histiocyte S. Lack of bone lesions at diagnosis is associated with inferior outcome in multisystem langerhans cell histiocytosis of childhood. Br J Haematol. 2015;169:241-8. doi:10. 1111/bjh.13271

12. Haupt R, Minkov M, Astigarraga I, Schafer E, Nanduri V, Jubran R, Egeler RM, Janka G, Micic D, Rodriguez-Galindo C, Van Gool S, Visser J, Weitzman S, Donadieu J, Euro Histio N. Langerhans cell histiocytosis (LCH): guidelines for diagnosis, clinical work-up, and treatment for patients till the age of 18 years. Pediatr Blood Cancer. 2013:60:175-84. doi:10.1002/pbc.24367.

13. Tan G, Samson I, De Wever I, Goffin J, Demaerel P, Van Gool SW. Langerhans cell histiocytosis of the cervical spine: a single institution experience in four patients. J Pediatr Orthop B. 2004;13:123-6.

14. Hung YC, Chang FC, Chen YW, Liang ML, Chen HH, Hsu SP, Yang HC, Wong TT. Langerhans' cell histiocytosis in the pediatric spine: therapeutic dynamic change of spinal deformity. Child's nervous system : ChNS : official journal of the International Society for Pediatric Neurosurgery. 2012;28:1243-50. doi:10.1007/s00381-012-1764-2.

15. Tan HQ, Li MH, Wu CG, Gu YF, Zhang H, Fang C. Percutaneous vertebroplasty for eosinophilic granuloma of the cervical spine in a child. Pediatr Radiol. 2007; 37:1053-7. doi:10.1007/s00247-007-0575-1.

16. Mavrogenis AF, Rimondi E, Ussia G, Rossi G, Ruggieri P. Successful treatment of a bifocal eosinophilic granuloma of the spine with $\mathrm{CT}$-guided corticosteroid injection. Orthopedics. 2011;34:230. doi:10.3928/014774447-20110124-29.

17. Zheng W, Wu J, Wu Z, Xiao J. Atlantoaxial instability secondary to eosinophilic granuloma of the axis in adults: long-term follow-up in six cases. The spine journal : official journal of the North American Spine Society. 2014;14:2701-9. doi:10.1016/j.spinee.2014.03.013. 
18. Durrani AA, Mangano F, Crawford A, Desai R, Chavanne A, Serrano L. Is instrumented screw fixation of $\mathrm{C} 1$ and $\mathrm{C} 2$ a safe and effective alternative for pediatric cervical spine instability? In: Proceedings of the NASS 23rd Annual Meeting. 2008

19. Sayhan S, Altinel D, Erguden C, Kizmazoglu C, Guray M, Acar U. Langerhans cell histiocytosis of the cervical spine in an adult: a case report. Turk Neurosurg. 2010;20:409-12. doi:10.5137/1019-5149.JTN.1625-08.2.

20. Sohn MJ, Park HC, Park HS, Kim JJ, Kim EY. Anterior cervical corpectomy and fusion using miniplate and screws in a 7-year-old child with eosinophilic granuloma of the cervical spine. Spine. 2001;26:1193-6.

21. Lu GH, Li J, Wang XB, Wang B, Phan K. Surgical treatment based on pedicle screw instrumentation for thoracic or lumbar spinal Langerhans cell histiocytosis complicated with neurologic deficit in children. The spine journal : official journal of the North American Spine Society. 2014;14:768-76. doi:10.1016/j. spinee.2013.06.104

Submit your next manuscript to BioMed Central and we will help you at every step:

- We accept pre-submission inquiries

- Our selector tool helps you to find the most relevant journal

- We provide round the clock customer support

- Convenient online submission

- Thorough peer review

- Inclusion in PubMed and all major indexing services

- Maximum visibility for your research

Submit your manuscript at www.biomedcentral.com/submit
Biomed Central 